(C) [2007] IEEE. Reprinted, with permission, from Min-Fu Hsieh, You-Chiuan Hsu and David G. Dorrell, Design of Large Power Surface-Mounted Permanent-Magnet Motors Using Post-Assembly Magnetization, Industrial Electronics Society, 2007. IECON 2007. 33rd Annual Conference of the IEEE 5-8 Nov. 2007]. This material is posted here with permission of the IEEE. Such ermission of the IEEE does not in any way imply IEEE endorsement of any of the University of Technology, Sydney's products or services. Internal or personal use of this material is permitted.

However, permission to reprint/republish this material for advertising or promotional purposes or for creating new collective works for resale or redistribution must be obtained from the IEEE by writing to pubs-permissions@ieee.org. By choosing to view this document, you agree to all provisions of the copyright laws protecting it 


\title{
Design of Large Power Surface-Mounted Permanent-Magnet Motors Using Post- Assembly Magnetization
}

\author{
Min-Fu Hsieh, Member, IEEE, You-Chiuan Hsu, Student Member, IEEE, and David G. Dorrell, \\ Member, IEEE
}

\begin{abstract}
This paper reports the design process for the manufacture of higher power rare-earth permanent-magnet motors using post-assembly magnetization. With these machines, difficulties can be encountered in production using normal manufacturing processes due to the high intensity of rare-earth magnets that are pre-magnetized. Post-assembly magnetization utilizes the stator windings of a permanent-magnet motor to magnetize the magnets after complete assembly (so that the problem can be solved). However, with post-assembly magnetization, some parameters such as slot-fill factor, number of turns, wire diameter, etc., must be considered for the magnetization, as well as the motor operation. The machine design should be able to meet the required specification as a motor and ensure correct magnetization is possible. In this paper, a design process is described that incorporates the design considerations for post-assembly magnetization (for the requirements for complete magnetization) together with the design requirements for successful motor operation. A $6 \mathrm{~kW}$ surface-mounted permanent-magnet motor is designed using the proposed process, and finite element analysis verifies the feasibility of the presented method.
\end{abstract}

Index Terms-post-assembly magnetization, SPM, permanentmagnet motor, motor design

\section{INTRODUCTION}

$\mathrm{R}^{2}$ are-earth permanent-magnet (PM) brushless motors are now widely used because of their high efficiency, high torque/power density and maintenance-free operation. This is particularly relevant to applications such as solar-power water pumping where these characteristics are very important. These machines are usually assembled with the magnets premagnetized (as apposed to ferrite magnet machines which are often magnetized once assembled). However, as the motor size and output power increase, the handling of the premagnetized components can be very difficult; and debris can adhere to the magnetic components causing further issues. These consequently increase the manufacturing cost [1][2]. To highlight the differences in manufacturing techniques, Fig. 1

Manuscript received April 16, 2007.

M.-F. Hsieh and Y.-C. Hsu are with the National Cheng Kung University, Tainan, Taiwan (phone: +88662747018 ext.216; fax: +88662747019 ; e-mail: mfhsieh@mail.ncku.edu.tw and p1895107@mail.ncku.edu.tw).

David G. Dorrell is with the University of Glasgow, Scotland, UK. (phone: +44 141 3302768; email: d.dorrell@elec.gla.ac.uk) presents the conventional manufacture process for rare-earth PM motors while Fig. 2 presents the process with postassembly magnetization used here. As already mentioned, problems occur in the steps of magnet insertion and rotor assembly. Therefore, with this process, it is difficult to produce large PM motors with high power (into the kilowatt range). Post-assembly magnetization represents a more satisfactory solution to these manufacturing problems. Here, the motor is fully assembled before the magnets are magnetized (by applying a current pulse to the motor stator windings). This is commonly used when manufacturing cheaper and lower power ferrite magnet machines. As can be seen in Fig. 2, the magnetization is performed in the last step and hence the assembly of the machine is much more straightforward.

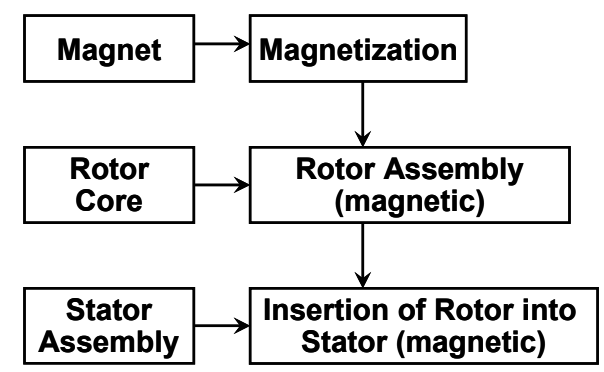

Fig. 1. Conventional manufacture process for PM motors.

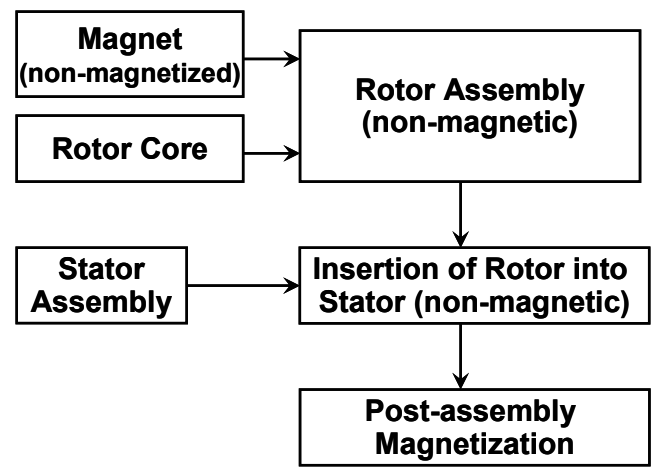

Fig. 2. Manufacture process with post-assembly magnetization.

Post-assembly magnetization techniques have been discussed in the literature [1-6]. Among these studies, most of 
the cases (references [1-5]) employed magnetizing fixtures to perform magnetization on assembled rotors or completed motors. Reference [6] mainly focused on magnetizer design. However, in these references, no design criteria were put forward for permanent motor manufacture with post-assembly magnetization. The different manufacturing processes which are normally applied to a variety of PM machines were compared in [7], and this paper highlighted that low energy magnets are usually post-assembly magnetized while high energy magnets are pre-assembly magnetized.

This paper presents a design procedure for a rare-earth SPM motor for manufacture with the post-assembly magnetization process. In the design procedure, magnetic circuit modeling is used in conjunction with a process that includes the requirements for the post-assembly magnetization. During post-assembly magnetization, a large current impulse is required to fully magnetize the magnets; and such current usually creates a large magnetic field that saturates the stator core material. The material relative permeability becomes almost unity at the instant of magnetization. This can be verified by finite element simulation. This paper makes use of this phenomenon in the design derivation for post-assembly magnetization. A 4-pole, 18-slot SPM motor with $6 \mathrm{~kW}$ output is designed with the proposed process. The design is then simulated with a finite element model. The simulation results demonstrate the feasibility of the proposed design process.

This paper is arranged as follows. In Section II, the design process with post-assembly magnetization is described. Section III discusses the motor designed with the proposed method and the simulations are presented. Conclusions are finally given in Section IV.

\section{DESIGN CRITERIA}

\section{A. Material Permeability at Post-assembly Magnetization}

The post-assembly magnetization design method proposed in this paper assumes a high material saturation level due to the large field intensity. This needs to be verified at the preliminary design stage. As shown in Fig. 3(a), an iron core is placed in the air with a coil placed around it. An MMF (due to a very large current pulse) generates a high magnetic field through the core with perpendicular flux. As can be seen, the way the flux lines penetrate the iron core is as though there was no change in magnetic material. This indicates that, for an SPM motor magnetized with a very large current pulse, the permeability of the iron core can be approximated to that of air during the magnetization pulse. In Fig. 3(b), the permeability for the case in Fig. 3(a) is plotted against the field intensity [8]. It can be found that the permeability almost reaches unity at very large intensity.

The current required for post-assembly magnetization to fully magnetize the magnets is approximately 3-4 times the coercivity current [5]. Therefore, from the above simulation, it can be demonstrated that the material permeability can be treated as "unity" when performing post-assembly magnetization. This is a critical point because the developed design approach can ignore the stator core material when deriving the magnetic circuit equations during magnetization.

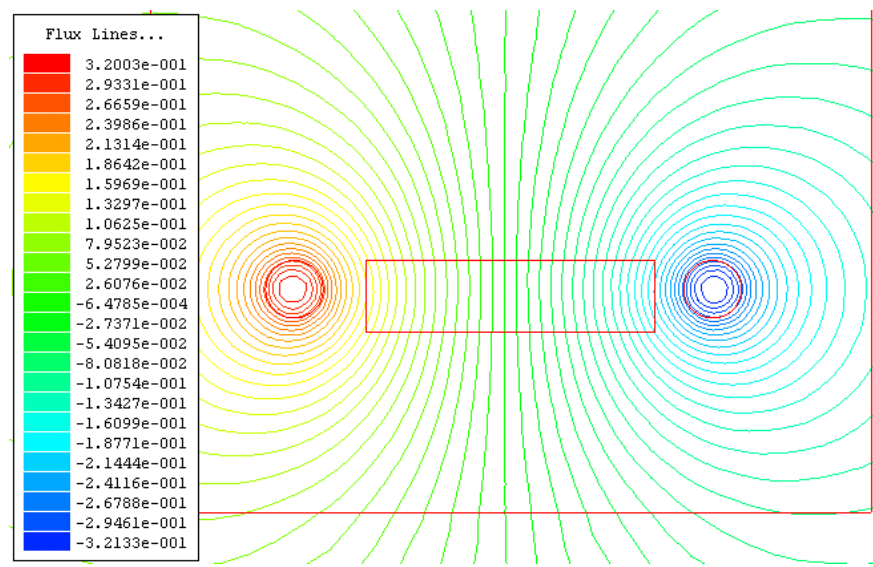

(a)

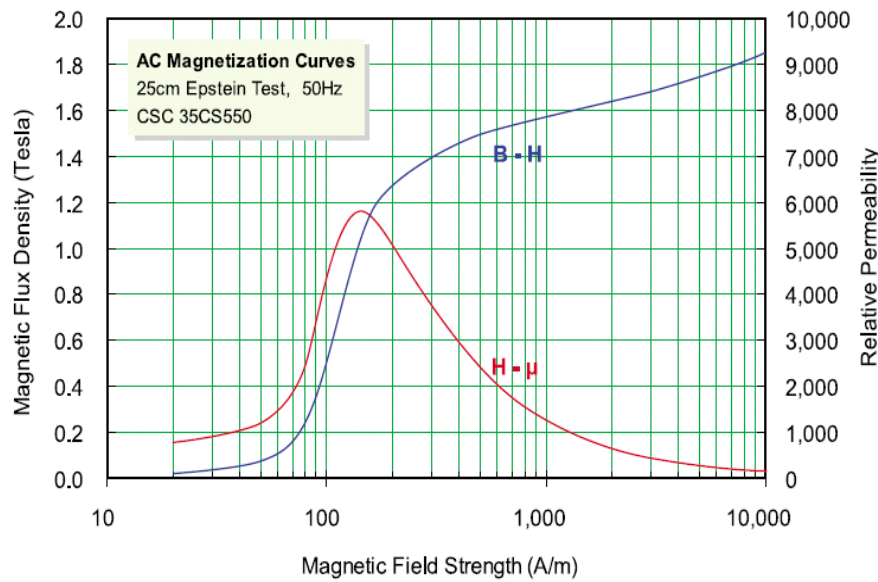

(b)

Fig. 3. Material permeability: (a) flux lines at high magnetic intensity and (b) the magnetic property of a commercial material

\section{B. Derivation of Design Process}

For a motor with prescribed specification, a certain back EMF constant is defined prior to the design of the motor. The given line-to-line back EMF constant can be described by (modified from reference [9])

$$
K_{E}=2\left(2 N B_{g} L_{s t} r_{o} N_{c o i l}\right)
$$

where $K_{E}$ is the line-to-line back EMF constant, $N$ is the number of turns per coil, $B_{g}$ is the air-gap flux density, $L_{s t}$ is the motor stack length, $r_{o}$ is the rotor radius and $N_{\text {coil }}$ is the number of coils per phase.

The rotor volume $V_{\text {rotor }}$ can be given as

$$
V_{\text {rotor }}=\pi r_{o}^{2} \times L_{s t}
$$

For a given output power density $D_{\text {power }}$ (based on the rotor volume $V_{\text {rotor }}$ ), the following relationship can be found:

$$
L_{s t}=\frac{\text { power }}{V_{\text {rotor }} D_{\text {power }}}
$$


From (1) and (3), the number of turns per coil for motor normal operation can be expressed as

$$
N=\left(\frac{\pi K_{E} D_{\text {power }}}{4 \times \text { power } \times B_{g} N_{\text {coil }}}\right) r_{o}
$$

Among the factors in (4), $K_{E}, D_{\text {power }}$ and power are given in the specification. $N_{\text {coil }}$ can be easily obtained from the common winding approach once the topology is decided (4pole, 18-slot) since the winding has to meet both the motoring and magnetizing requirements. Finally, $B g$ can also be determined from magnetic circuit modeling, which will not be detailed here. Therefore, the only factors to be found are the rotor radius and the number of turns per coil, which is critical to the magnetization.

The "equivalent spot" (Point A) shown in Fig. 4 represents the MMF center when conducting the post-assembly magnetization. Point $\mathrm{C}$ is the center of the magnet arc. The flux generated by the MMF center at Point $\mathrm{A}$ has a tangential direction at $\mathrm{C}$ (when referred to the radius $\overline{A C}$ around point A) as indicated by the arrow.

The magnetic flux density required to magnetize the magnet $B_{o}$ can be defined by

$$
B_{o}=\frac{\mu_{o} I_{m a g}}{4 \pi \overline{A C}}
$$

where $I_{m a g}$ is the magnetizing current. Note that in Fig. 4, the parameter $l$ in the equation for $B_{o}$ means $\overline{A C}$, which can be expressed as

$$
\begin{aligned}
\overline{A C} & =\sqrt{(\overrightarrow{A B})^{2}+(\overrightarrow{B C})^{2}} \\
& =\sqrt{\left[\frac{R_{o}+r_{o}}{2} \sin \left(\frac{\pi}{2 N_{m}}\right)\right]^{2}+\left[\frac{R_{o}+r_{o}}{2} \cos \left(\frac{\pi}{2 N_{m}}\right)-r_{0}\right]^{2}}
\end{aligned}
$$

where $N_{m}$ is the number of poles and $R_{o}$ is the radius of the slot end as indicated in Fig. 4.

Therefore, for a known $B_{o}$ (required to magnetize the magnet) the geometric relationship in Fig. 4 can be used to calculate the corresponding current for magnetization. (5) and (6) can be combined to find the relationship between $I_{m a g}, R_{o}$ and $r_{o}$ for the required magnetizing flux density $B_{o}$. This relationship is important and will be detailed later.

The slot-fill factor is a critical factor for design with postassembly magnetization. This is because the conditions for both magnetization and motoring operation should both be satisfied. Wire with large diameter should be used for postassembly magnetization to withstand the large magnetizing current. However, sufficient turns are also needed to generate the field intensity required for magnetization. Also, under the specified rated current density (or rated current) for motoring operation, the ampere-turn (i.e., the electric loading) is another factor to consider. For the design process being described here, half of the slot area (as shown in Fig. 5) can be expressed by the area in the DEFG box multiplied by a shape factor, $K_{s}$. This factor depends on the tooth shape and design experience.

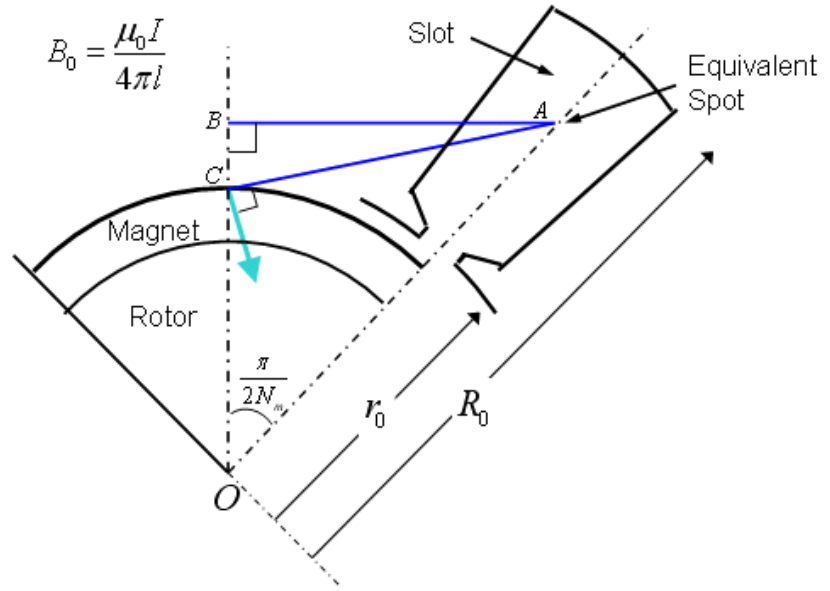

Fig. 4. MMF center and flux density for magnetization.

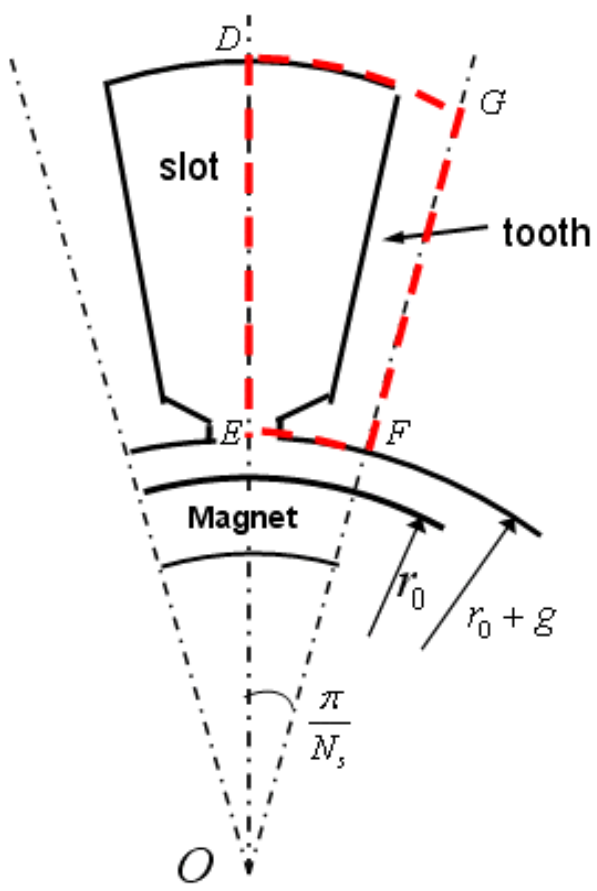

Fig. 5. Slot geometry.

Therefore, for the rated current $I_{\text {rated }}$ and the current density $D_{\text {current }}$, the slot-fill factor $K_{S F}$ can thus be expressed as

$$
\begin{aligned}
K_{S F} & =\frac{I_{\text {rated }} N}{K_{s} A D_{\text {current }}} \\
= & \frac{\text { power } \times N N_{s}}{K_{s}\left[R_{o}^{2}-\left(r_{o}+g\right)^{2}\right] \pi D_{\text {current }}}
\end{aligned}
$$

where $A$ is the area of the DEFG box shown in Fig. 5, and $g$ is the air-gap length.

Combining (4) and (7), the following equation can be derived:

$$
R_{o}=\sqrt{\frac{K_{E} D_{\text {power }} N_{s} r_{o}}{2 N_{\text {coil }} K_{S F} K_{s} D_{\text {current }} B_{g}}+\left(r_{o}+g\right)^{2}}
$$


where $N_{s}$ is the number of slots.

From (8), for a given slot-fill factor and back EMF constant, the relationship between $R_{o}$ and $r_{o}$ can be determined. This will give a series of $R_{o}$ and $r_{o}$ combinations and hence another condition is defined for the determination of the motor size. In addition, a condition is given by (5) and (6), where each magnetizing current $I_{m a g}$ will give ranges for $R_{o}$ and $r_{o}$. With the above two conditions, the motor size, defined by $r_{o}$ and $R_{o}$, can thus be determined. However, in the proposed design process, the $R_{o}$ and $r_{o}$ relationship is first given by the specifications (e.g., the slot-fill factor and back EMF constant). For a chosen $R_{o}$ and $r_{o}$ combination, the magnetizing current can then be determined. A computer program has been developed using this numerical method to calculate the magnetizing current.

So far the motor has not been completely designed. For the rest of the detailed dimensions of the motor, a common magnetic circuit modeling process can be applied to complete the design process.

\section{DESIGN RESUltS AND SiMULATION}

\section{A. Initial Design Specification}

The SPM motor has a specification as listed in Table I. The motor is required to operate at $310 \mathrm{~V}$ with an output power of $6 \mathrm{~kW}$. The rated and no-load speeds are $6000 \mathrm{RPM}$ and 7000 RPM respectively.

TABLE I

SPM MOTOR SPECIFICATIONS

\begin{tabular}{cc}
\hline \hline Rated voltage (V) & 310 \\
Output power (kW) & 6 \\
Rated speed (RPM) & 6000 \\
No-load speed (RPM) & 7000 \\
Rated input current (A) & 19.35 \\
Current density (A/mm ( $^{2}$ & 10.2 \\
Line-to-line peak back EMF constant & 0.423 \\
(V*sec/rad) & 45 \\
Slot-fill factor (\%) & $\mathrm{Br}=1.243 \mathrm{~T}$ \\
Magnet (NdFeB) & $\mathrm{Hcb}=11.82 \mathrm{kOe}$ \\
\end{tabular}

The curves in Fig. 6 show the relationship of $r_{o}$ and $R_{\mathrm{o}}$ for the defined back EMF constant, slot-fill factor together with curves for the magnetizing current (plotted from the equations previously derived). The dashed curve in Fig. 6 indicates the $r_{o}$ and $R_{\mathrm{o}}$ relationship for the prescribed back EMF constant $\left(K_{E}=0.423\right)$ and slot-fill factor $\left(K_{S F}=45 \%\right)$. Each of the solid curves represents the $r_{o}$ and $R_{\mathrm{o}}$ relationship due to a magnetizing current $I_{\text {mag }}$, and a series of curves for $I_{\text {mag }}=6,12$, 18 and $24 \mathrm{kA}$ is plotted. The intersection points between the solid curves and the dashed curve produces possible $r_{o}$ and $R_{\mathrm{o}}$ combinations subject to the given criteria described above. As shown in Fig. 6, a motor with a larger $r_{o}\left(R_{\mathrm{o}}\right)$ requires a higher magnetizing current. For the case designed in this paper, the motor has $r_{o}=35 \mathrm{~mm}$ and $R_{\mathrm{o}}=46 \mathrm{~mm}$ and hence the magnetizing current required is $18 \mathrm{kA}$. Note that the form of the solid curves is due to the complex relationships between $I_{m a g}, R_{o}$ and $r_{o}$.

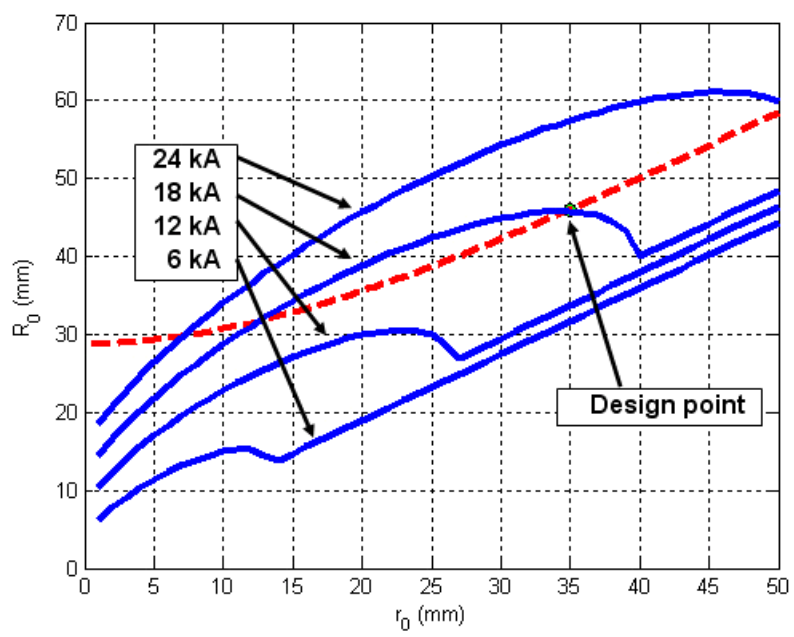

Fig. 6. $r_{o}$ and $R_{\mathrm{o}}$ relationship.

\section{B. Magnetization Validation and Temperature Rise}

The designed SPM motor, as well as the magnetization impulse flux plot, is shown in Fig. 7, and the parameters are given in Table II while the winding layout is illustrated in Fig. 8 for one phase. The magnetizing current is injected via two phases of a star connected winding and there are two parallel connections (of three series coils) per phase. The magnetizing simulation was carried out using Ansoft finite element software. The current was set at $18 \mathrm{kA}$ for the coil current. The motor has been correctly designed so that the winding generates a magnetic flux with four equivalent MMF centers. This magnetizes a four-pole rotor in the correct fashion for a four-pole motor. The flux pattern illustrates that there is very high saturation since the flux lines penetrate the iron core as though it is penetrating air (i.e., no material boundary change). This demonstrates that at the magnetization moment the permeability of the materials is equivalent to the air.

However, this current level, even for a small $10 \mathrm{~ms}$ pulse, is very high. The temperature rise can be estimated using the equation [10]

$$
\begin{aligned}
d T & =\frac{P d t}{C}=\frac{I_{\text {pulse }}^{2} 2 R_{\text {phase }}\left({ }^{\circ} \mathrm{C}\right) \times \Delta t}{C_{\text {specific heat capacity }}^{\mathrm{cu}} 2 \times \text { phase winding copper weight }} \\
& =\frac{I_{\text {pulse }}^{2} \times 2 \times R_{\text {phase }}\left[20^{\circ} C\right](1+0.0039 T) \times \Delta t}{380 \times 2 \times \text { phase winding copper weight }}
\end{aligned}
$$

where the temperature change is $\mathrm{d} T$, the power dissipated is $P$, $\mathrm{d} t$ is the pulse period and $\Delta t$ is the iterative time step. This is an estimate and assumes a constant specific heat capacity.

This equation yields a value of $600{ }^{\circ} \mathrm{C}$ temperature rise for $18 \mathrm{kA}$ (in each parallel winding path) in $0.7 \mathrm{~ms}$ which is clearly too high. However, the simulation work in [10] and the practical investigation in [11] illustrated that it is not necessary to use a magnetizing field that is four time the coercivity. In fact it was found that a value much less than this is sufficient to magnetize the magnets - probably as low as 
$1500 \mathrm{kA} / \mathrm{m}$ for this strength of magnet will obtain magnetization to within $10 \%$ full magnetization. If the magnetizing current is set to $2 \mathrm{kA}$ in each parallel path then the magnetic field intensity is still sufficient to magnetize the magnets to within a few percent of full magnetization. This is shown in Fig. 9 where field intensities are noted in different parts of the magnet. At $2 \mathrm{kA}$ coil current the temperature rise using (9) is now only $63{ }^{\circ} \mathrm{C}$ during a $10 \mathrm{~ms}$ pulse. Therefore if this is insufficient then there is still capacity for increased magnetizing current if necessary. This is before forced cooling is used.

TABLE II

MOTOR PARAMETERS

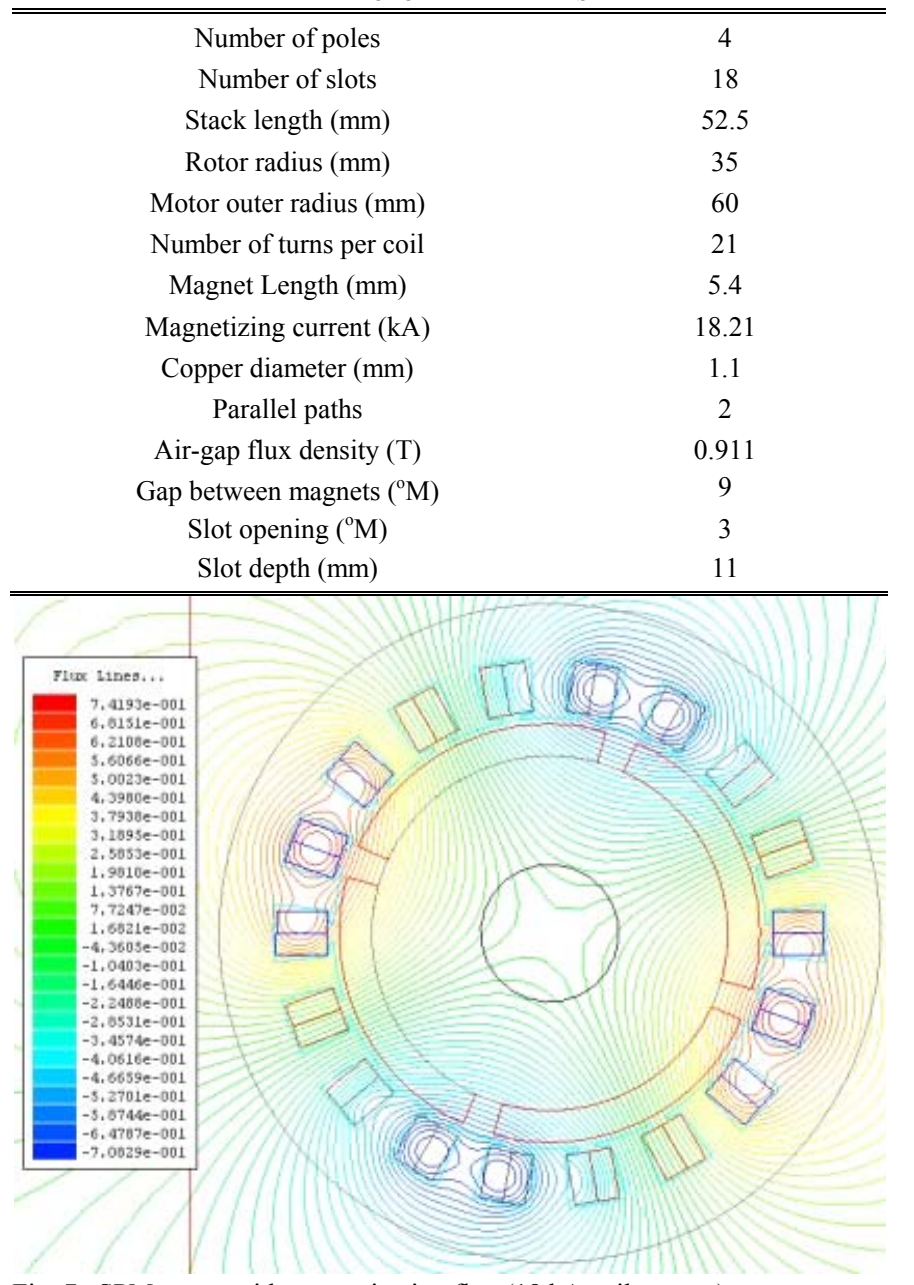

Fig. 7. SPM motor with magnetization flux (18 kA coil current).

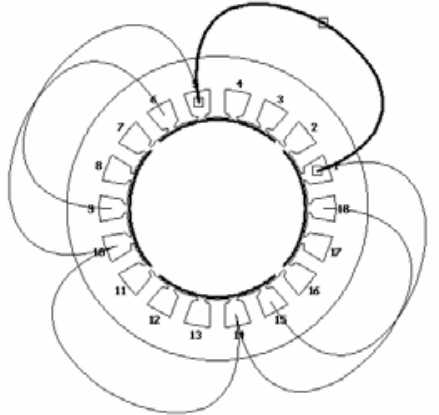

Fig. 8. Coil arrangement for one phase (two parallel paths formed from three series coils).

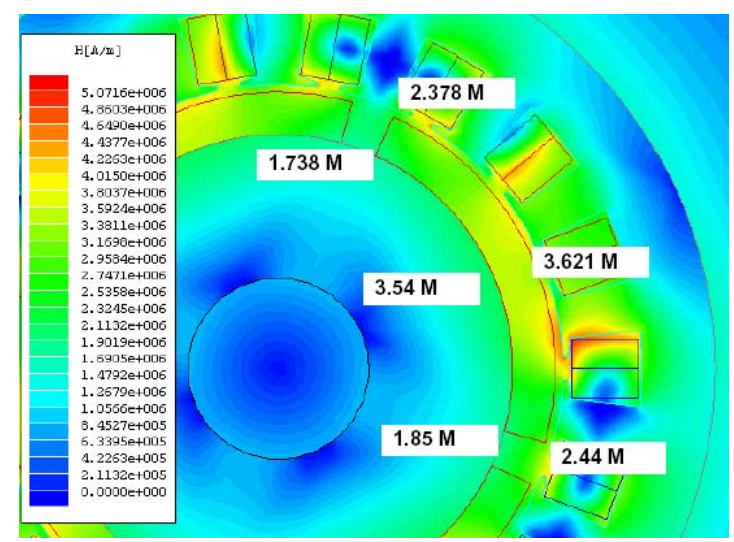

Fig. 9. Magnet field intensities at different parts of the magnet during magnetization (with $2 \mathrm{kA}$ coil current). These are sufficient to magnetize the machine.

\section{Motor Performance Simulation}

The finite element simulation results on open circuit (using SPEED PC-FEA motor design software from The University of Glasgow) are presented in Figs. 10 and 11 for the phase and line-to-line back EMFs respectively. It is found that the designed motor has a back EMF constant matched to the specification. The operation was also tested using SPEED PC$\mathrm{BDC}$ with is an industry-standard spreadsheet analytical deign package. The open-circuit back-EMF was almost identical to the finite element waveforms in Figs. 10 and 11.

Under load, PC-BDC and PC-FEA delivered similar torques (9.64 and $9.29 \mathrm{Nm}$ respectively), these are within 3.6 $\%$ of each other. At the rated speed $(6000 \mathrm{rpm})$ and current (rms of trapezoidal $=19.35 \mathrm{~A}$ ) and under d.c. control, PCBDC calculates that the machine delivers $5875 \mathrm{~W}$ (which is within $2.1 \%$ of the specification). The efficiency is $94.1 \%$ were there is $183 \mathrm{~W}$ of copper loss, $130 \mathrm{~W}$ of iron loss, $52 \mathrm{~W}$ of magnet loss (this can be reduced by use of an internal magnet rotor) and $183 \mathrm{~W}$ of mechanical loss (this is somewhat arbitrary and dependent on the bearing quality and windage loss). Obviously the iron loss is dependant on the quality of steel, however efficiencies approaching $90 \%$ and even exceeding this are quite usual in a rare-earth PM brushless machine. The I-psi (current against flux linkage) plot is shown in Fig. 12. The area enclosed within the loops represents the work done per phase. PC-FEA gives a slightly lower torque hence the loop area is slightly smaller. Thus, the design process proposed in this paper had been verified using finite element and industry-standard design tools.

To design a motor with an even higher power rating, the design process can be applied subject to the limitations of the magnetizer used. 


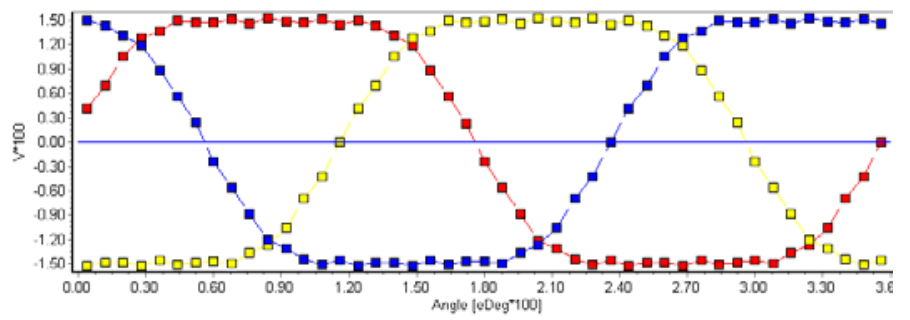

Fig. 10. Phase back-EMF SPEED PC-FEA (peak=155 V).

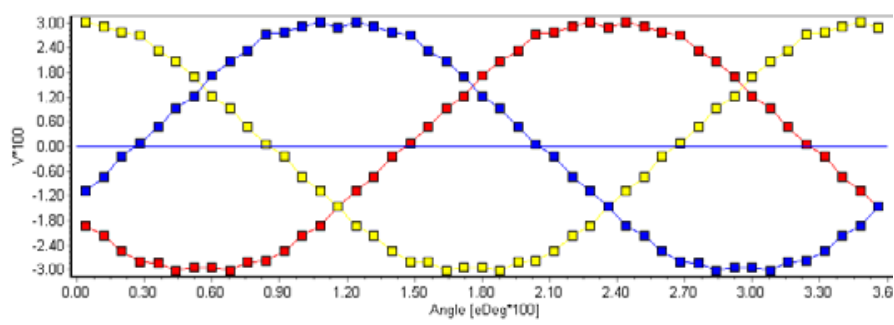

Fig. 11. line-to-line back-EMF from SPEED PC-FEA (peak = $305 \mathrm{~V})$.

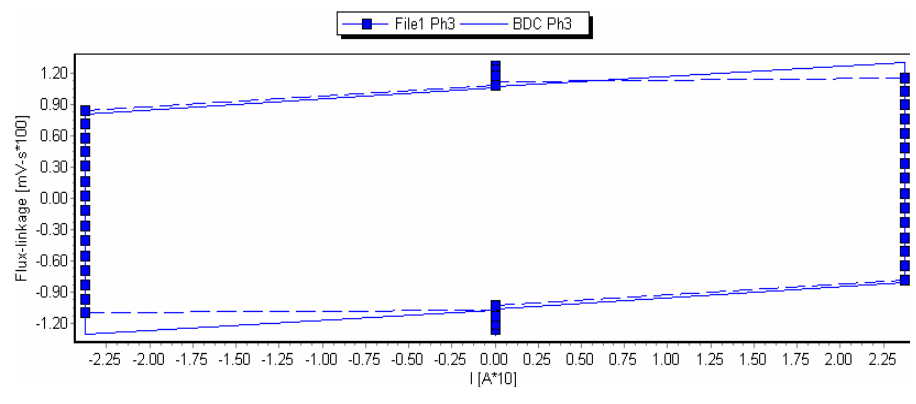

Fig. 12. I-psi comparison from SPEED PC-FEA (File Ph3) and PC-BDC (BDC Ph3).

\section{CONCLUSION}

A method for designing a rare-earth surface PM motor which is magnetized after assembly has been put forward and verified using finite element analysis. It is used to design a 4pole $6 \mathrm{~kW}$ machine as an example. The magnetization was investigated - previous studies [10][11] indicated that it is not necessary to use the theoretical design magnetization current, and that a significantly less current can produce almost full magnetization. This was utilized to ensure that the magnetizing current was reduced to be within a temperature rise limit for the pulse period. This proved successful. The performance was verified using SPEED PC-FEA and PC$\mathrm{BDC}$ and it was found to meet the specification.

\section{ACKNOWLEDGMENT}

This work was supported by the National Science Council of Taiwan R.O.C. under contract NSC 95-2221-E-006-471.

\section{REFERENCES}

[1] C. K. Lee and B. I. Kwon, "Design of post-assembly magnetization system of line start permanent-magnet motors using FEM," IEEE Trans. Magn., vol. 41, no.5, pp. 1928-1931, 2005.

[2] G. W. Jewell and D. Howe, "Computer-aided design of magnetizing fixtures for the post-assembly magnetization of rare-earth permanent magnet brushless DC motors," IEEE Trans. Magn., vol.28, no.5, pp. 3036-3038, 1992.

[3] Y. Okada, H. Inoue, H. Fusayasu, and H. Nishida, "Analysis for permanent magnet motor taking account of magnetizing process, "IEEE Trans. Magn., vol.33, no.2, pp. 2113-2116, 1997.

[4] Y. Zhilichev, P. Campbell and D. Miller, "In Situ magnetization of isotropic permanent magnets," IEEE Trans. Magn., vol. 38, no.5, pp. 2988-2990, 1991

[5] P. Zheng, Y. Liu, Y. Wang, S. Cheng, "Magnetization analysis of the brushless DC motor used for hybrid electric vehicle," IEEE Trans. Magn., vol. 41, no. 1, pp. $522-524,2005$.

[6] L. Chang, T. R. Eastham and G. E. Dawson, "In Situ magnetization of $\mathrm{NdFeB}$ magnets for permanent magnet machines," IEEE Trans. Magn., vol. 27, no.5, pp. 4355-4359, 1991.

[7] S.K Pal, "Comparative study of the design and manufacturing processes of electrical motors with low and high energy permanent magnets, " IEE Electrical Machines and Drives Conference, 1993, 8-10 Sept, pp 339 346.

[8] China Steel Corporation, Product specification of magnetic steel.

[9] D. Hanselman, Brushless Permanent Magnet Motor Design. The Writers' Collective, 2003.

[10] D. G. Dorrell, M.-F. Hsieh, and Y.-C. Hsu, "Post Assembly Magnetization Patterns in Rare Earth Permanent Magnet Motors," accepted for IEEE Transactions on Magnetics, June 2007.

[11] M.-F. Hsieh and Y.-C. Hsu, "Characteristics Regulation for Manufacture of Permanent-Magnet Motors Using Post-Assembly Magnetization," accepted for IEEE Transactions on Magnetics, June 2007. 